\title{
Violência contra a mulher do campo: desafios às políticas públicas*
}

\author{
Violence against rural women: challenges for public policies
}

\author{
Patricia Krieger Grossi** \\ Ana Rita Costa Coutinho***
}

\section{Resumo:}

$\mathrm{O}$ artigo tem por objetivo analisar algumas das expressões de violência vivenciadas por mulheres do campo e as experiências relacionadas ao acesso à rede de proteção social no Rio Grande do Sul. O estudo foi exploratório, de natureza qualitativa e norteado pelo método dialético-crítico. As narrativas das mulheres do campo, lideranças e trabalhadores da rede foram obtidas a partir de entrevistas semi-estruturadas e analisadas à luz dos estudos de gênero. Os resultados apontam para dificuldades de acesso e/ou inexistência de serviços da rede para as mulheres rurais, além de experiências sociais marcadas pela divisão sexual do trabalho, patriarcalismo e machismo.

Palavras-Chave: Violência. Mulher do campo. Gênero. Políticas públicas.

\begin{abstract}
:
The article has the objective to analyse some expressions of violence experienced by rural women and the experiences related to access to the social protection network in Rio Grande do Sul. The study was exploratory, from a qualitative nature and guided by the dialectical-critical method. The narratives of rural women, leaders and network workers were obtained from semi-structured interviews and analyzed in the light of gender studies. The results point to difficulties of access and / or lack of network services for rural women, as well as social experiences marked by sexual division of labor, patriarchy and machismo.
\end{abstract}

Keywords: Violence. Rural women. Gender. Public policies.

\section{Introdução}

Os movimentos sociais rurais, especialmente o movimento feminista campesino têm tido um papel importante no que tange às políticas públicas. Um exemplo disso foi o avanço na efetivação da política de assentamentos e na conquista de direitos como a previdência social rural e o crédito agrícola voltado especificamente para a agricultura familiar. Além dessas conquistas, os movimentos de mulheres rurais lutam pela redução das desigualdades de gênero arraigadas culturalmente no campo.

\footnotetext{
* Essa pesquisa contou com apoio financeiro do CNPQ através da Chamada Universal MCTI/CNPq no14/2012.

** Professora Adjunta do curso de Serviço Social da Escola de Humanidades da PUCRS. Mestrado em Serviço Social pela PUCRS. PhD em Serviço Social pela Universidade de Toronto, Canadá. Especialista em Gerontologia Social pela PUCRS. Pesquisadora Produtividade em Pesquisa 1C do CNPq. E-mail: pkgrossi@pucrs.br *** Bacharel em Serviço Social pela PUCRS. Mestra em Serviço Social pela PUCRS. Doutoranda em Serviço Social pela PUCRS. Integrante do Grupo de Estudos e Pesquisa em Violência - NEPEVI da PUCRS. E-mail: anaritars@hotmail.com
} 
No entanto, quando nos aproximamos dessa realidade, principalmente das experiências sociais das mulheres rurais, percebemos que a luta pela igualdade de gênero ainda apresenta muitos desafios. Entre os desafios, podemos citar: a falta de uma rede especializada para o enfrentamento à violência contra a mulher, a cultura machista e patriarcal, a falta de conhecimento dos direitos, o desconhecimento sobre a Lei Maria Penha e a tripla jornada de trabalho em que a mulher do campo está sujeita.

\section{Procedimentos Metodológicos}

Marconi e Lakatos (1999, p.94) definem a entrevista como sendo o encontro entre duas pessoas, a fim de que uma delas obtenha informações a respeito de determinado assunto, mediante uma conversação de natureza profissional. Foram realizadas entrevistas semiestruturadas, aplicadas com base num formulário (sistema de coleta de dados que permite obter informações diretamente das mulheres entrevistadas), contendo perguntas abertas e fechadas, enfocando nas características sociodemográficas das mesmas. As entrevistas também foram realizadas com informantes chaves da rede de proteção à mulher para identificar as mulheres rurais em situação de violência doméstica e as próprias mulheres indicaram outras que estavam vivenciando a mesma situação, técnica conhecida como snowball technique ou "bola de neve" (CASTILLO, 2009).

Posteriormente, foi realizada a coleta de dados através de realização de grupo focal, centrando-se na experiência com a Lei Maria da Penha e a rede de proteção à mulher e formas de acesso. Compreende-se o grupo focal como sendo um grupo de discussão informal, de tamanho reduzido onde se pretende observar o processo através do qual os participantes especialmente selecionados respondem às questões da pesquisa para que, posteriormente, possam os dados serem teoricamente interpretados (BARBOSA, 1999).

Foram realizados oito grupos focais com mulheres no meio rural de municípios do interior do Rio Grande do Sul de diferentes regiões Funcionais do Estado, contemplando em torno de 40 mulheres. 0 objetivo foi identificar, na perspectiva destas usuárias, a concepção de violência, se as demandas e necessidades tem sido contempladas, o conhecimento da Lei Maria da Penha e a rede de apoio acessada (tanto formal como informal) na busca do rompimento das situações da violência, entre outros aspectos emergentes no grupo. Também foram entrevistadas lideranças campesinas e profissionais da rede de serviços de 
proteção à mulher, totalizando 18 sujeitos. As entrevistas e grupos focais foram gravados e posteriormente, transcritos, sendo submetido o corpus para análise. Para se analisar as narrativas, adotou-se a análise de conteúdo, a autora conceitua a análise de conteúdo como “[...] um conjunto de técnicas de análise de comunicação visando obter, por procedimentos sistemáticos e objetivos de descrição do conteúdo das mensagen". Significa dizer que a inferência de conhecimentos, é relativa às condições de "[...] produção/ou de recepção destas mensagens" (BARDIN, 1977, p.42).

Já para Minayo (1998) explica que o termo significa mais do que um procedimento técnico, fazendo parte de uma histórica busca teórica e prática no campo das investigações sociais. Do ponto de vista operacional, complementa a autora, a análise de conteúdo parte de uma literatura de primeiro plano para atingir um nível mais aprofundado: aquele que ultrapassa os significados manifestos. Em termos gerais, explica a autora, relaciona estruturas semânticas (significantes) com estruturas sociológicas (significados) dos enunciados, ou seja, "[...] articula a superfície dos textos descrita e analisada com os fatores que determinam suas características: variáveis psicossociais, contexto cultural, contexto e processo de produção da mensagem" (MINAYO, 1998, p. 203). No próximo sub-item, iremos apresentar os resultados da pesquisa através da vocalização das demandas e realidades vivenciadas pelas mulheres do campo do estudo.

\section{Violência Contra a Mulher do Campo: Desafios para a rede de Atendimento}

Na dimensão política, a gestão das políticas e dos recursos apresenta-se fragilizada, evidenciando o despreparo dos municípios em conduzir o processo de gestão pautado nas diretrizes e princípios do SUS e SUAS (GROSSI et al., 2015). A inexistência de agenda local direcionada à violência contra as mulheres que vivem no campo e a desresponsabilização e descompromisso da gestão local frente a esse fenômeno, são elementos que nos levam a problematizar a capacidade protetiva da rede, bem como sua real extensão no território rural gaúcho. A partir da análise dos dados da pesquisa evidencia-se que as ações desenvolvidas por alguns municípios são pontuais, desarticuladas e com pouca efetividade e alcance às mulheres em situação de violência conforme as narrativas a seguir: 
[...]no dia internacional das mulheres, todos os anos, a gente faz um encontro...mas aquelas que deveram ir lá, não vão. Muitas pessoas falam "bah, que pena que tal pessoa não esta aqui hoje", porque as que mais precisavam, não vão.(M-G)07.07.2015

[...] no dia da mulher, a gente sempre tem uma palestra e essa palestra é quase sempre relacionada à violência da mulher ou a autoestima,(M-G)07.07.2015

[...]No ano passado, nós fizemos alguns cursos, teve até em todo o Estado, serviços de capacitação profissional, de sensibilização e humanização no atendimento das vítimas, que era para os policiais no meio profissional se sensibilizarem (M-P) 07.07.2015

[...]ainda não tem nada sendo implementado ou sendo pensando diretamente pelo menos na parte da psicologia do posto Para esse público, até porque nós temos várias carências, no sentido de acesso a essas mulheres. (M-P)22.06.2015

Por fim, na medida em que a mulher vítima de violência acessa a rede de enfrentamento e atendimento, fica o seguinte desafio:

[...] porque qual é o desafio de hoje, a mulher que entra na rede, que procura a delegacia, em tese, ela não pode morrer pelo companheiro, não pode avançar o ciclo de violência. Esse é o desafio, é tu cortar com aquele ciclo de violência. (MP)07.07.2015

A ruptura com os processos de violência é o objetivo principal de toda e qualquer ação das redes de enfrentamento e atendimento às mulheres vítimas de violência. Porém, não é um processo fácil e para as mulheres que vivem em zonas rurais e periféricas tornase mais difícil. A partir do mapeamento da rede de apoio formal e informal existente à mulher na zona rural nos municípios da amostra, foi possível identificar as lacunas e necessidades. Na rede informal, destaca-se a importância da família, amigos e/ou vizinhos para a efetivação da denúncia. Na rede formal, o acesso ocorre através dos CRAS e Delegacias comuns principalmente, pois a maioria dos municípios pesquisados, em quase sua totalidade, não possui serviços da rede especializada. Diante desse contexto, urge a implementação de serviços especializados nos espaços rurais do Estado.

Ao buscarmos verificar o conhecimento das mulheres rurais sobre a Lei Maria da Penha e a forma de acesso aos serviços da rede de proteção, pudemos constatar um conjunto de dificuldades relativas ao desconhecimento, vergonha e ausência de serviços especializados. Embora existam serviços de atendimento nos campos da Segurança (delegacias), Assistência (CRAS) e Saúde (UBS), há falta de suporte e orientação na direção da superação da violência. 
No processo de Identificar de que forma a rede de proteção à mulher está contribuindo para o enfrentamento da violência contra as mulheres rurais, em suas múltiplas expressões, pode-se perceber que, embora minimamente, a rede contribui com ações pontuais de informação sobre legislação, acesso aos benefícios e medidas de proteção na forma da lei. Falta a ampliação de serviços de acolhimento e de articulação de políticas intersetoriais.

Quanto à falta de recursos públicos existentes no meio rural, as narrativas deixam claro que a distância até a rede de proteção é um fator obstaculizador na procura de apoio. As mulheres chegam a caminhar quilômetros nessa rota, e muitas vezes deparam-se com serviços não especializados de atendimento à mulher. Dessa forma, a violência contra a mulher rural, se expressa também na falta de recursos estruturais:

[...] A distância: lá tem que ser na cidade, fora não tem. Mas na cidade tem localidade lá, que dá 32 quilômetros da cidade. Eu moro 41 quilômetros da cidade (M-LR) 04.08.2015

[...] eu moro perto da cidade, a 17 quilômetros, mas tem lugares que é 60, 70 quilômetros da cidade. (M-LR 04.08.2015).

[...] Tem um lugar que passa ônibus uma vez por semana para a cidade, as estradas são ruins, então é difícil para as pessoas irem para a cidade (M-LR 04.08.2015).

[...] O primeiro é ter um espaço, né, um abrigo, um espaço de acolhimento, que nós podemos encaminhar elas. Porque normalmente quando uma mulher vem com uma situação de violência, tem que tentar acomodar com um familiar, achar alguém pra ficar com ela, enfim. Porque a gente não tem abrigo e nem tem convênio com nenhum abrigo. Então não tem onde pôr elas. ( M-P 01.08.2013).

As narrativas acima sugerem que a distância e /ou a falta de uma rede especializada no atendimento à mulher em situação de violência, pode incidir na tomada de decisão, ou seja, são fatores preponderantes na busca do enfrentamento à violência de gênero. Dessa forma, a violência praticada contra as mulheres, seja ela nas grandes cidades ou no campo, perpassa o âmbito privado e se perpetua em diversas esferas. Como consequência, uma mulher em situação de violência passa por diversos entraves ao tentar evadir-se de tal cenário. A falta de integralidade entre os serviços também se apresenta como um fator de risco às mulheres, contribuindo para revitimização das mesmas. A procura de apoio externo é outro fator que, muitas vezes, pode levar as mulheres ao sofrimento, seja pela insegurança ao comentar sua vida para outras pessoas, ou pelos 
intermináveis caminhos que percorrem na busca de soluções para as situações de violência. Quando a violência apresenta-se no modo de organização dos serviços, ou até mesmo na falta deles, chamamos esse desequilíbrio de violência estrutural, o que consequentemente resultará em outras violências. Peres (2002) argumenta que esta forma de violência atinge todos os segmentos sociais, porém afeta os mais vulneráveis, os quais são mais atingidos pela falta de acesso aos serviços públicos:

Desigualdade e exclusão sociais, desemprego, regime político e eficácia das instituições governamentais e de segurança pública são alguns dos fatores que, do ponto de vista macroestrutural, favorecem o desenvolvimento da violência. $O$ modo como esses determinantes são atualizados e expressos no cotidiano exemplificam os fatores conjunturais: aumento da criminalidade urbana, da delinquência juvenil, do crime organizado e da prostituição infantil, entre outros, são favorecidos por contextos marcados pela desigualdade social e impunidade e, por sua vez, favorecem a escala da violência em contextos específicos. Recentemente vem sendo dada importância aos fatores culturais e individuais que atuam como determinantes do comportamento violento, tais como atitudes, comportamentos e normas, padrões de relação familiar e de gênero, uso de drogas e álcool, entre outros (PERES, 2002, p. 54).

Segundo o Comitê Latino-Americano e do Caribe para a Defesa dos Direitos da Mulher (CLADEM, 2002), a cada 15 segundos uma mulher é espancada (2,1 milhões de mulheres espancadas por ano) no Brasil. Essa é uma situação que aflige também as famílias rurais, contudo, há poucos registros dessa modalidade de violência nas zonas rurais em decorrência do machismo e do patriarcado comuns a essas regiões, bem como da inexistência de Delegacias de Mulheres nas áreas rurais. Em entrevista com uma mulher rural, vítima de violência doméstica, que encontrava-se abrigada, observa-se a fragilidade da rede de proteção às mulheres, uma vez que esta residente precisou deslocar-se até o município mais próximo para realizar a denúncia contra ao agressor.

[...] ele tá na cidade, ele tá armado, ele anda te procurando, aí nisso eu tava na casa do meu pai, eles são separados e tal e eu fui lá. Ele perguntou se nós tínhamos brigado. Eu disse pro meu pai "fica com as crianças um pouquinho", ele perguntou "onde tu vai?", "na delegacia", "que que tu vai fazer na delegacia? tu vai dar parte do fulano?" eu digo "vou, vou dar parte dele porque eu não vou esperar o pior acontecer pra depois denunciar", que ele já tinha me chamado de vagabunda, de chinelona, com diversas agressões verbais. E eu disse que ele já tinha colocado a aliança na minha boca e disse "tu pega essa porqueira de aliança e engole", aí desde isso eu não falei mais com ele, não vi mais ele. Aí vim pra cá, vim parar aqui, fui na delegacia, fiz o B.O. na mesma hora me encaminharam pra cá, porque eu pedi pra eles, porque lá eu não tinha segurança nenhuma (MULHER RURAL). 
O relato da entrevistada revela que, muitas vezes, o medo, a vergonha e a falta de conhecimento para comunicar e acessar os órgãos responsáveis pela atenção a essa questão são apontados como os principais fatores que incidem para a continuidade das violências. A histórica invisibilidade da violência contra a mulher segundo Saffioti (2007) encontra-se intrinsecamente interligada aos fatores culturais que se estabeleceram ao longo do desenvolvimento da sociedade brasileira e da organização da família, densamente influenciada pelo modelo patriarcal e pela concepção machista, em que mulheres e crianças passam a ser consideradas como propriedades do homem - provedor da família.

Segundo Almeida (2007), a perpetuação da violência de gênero pode ser visível também pelo grau de tolerância do Estado frente à ausência de medidas eficazes, ou até mesmo pela deficiência de políticas públicas. Com o advento da Lei Maria Penha, foi definida em seu texto uma série de ações conjuntas de atenção e prevenção à violência doméstica, articuladas às ações governamentais da União, dos estados, dos municípios, órgãos não governamentais integrados através do Poder Judiciário, Ministério Público, Defensorias Públicas interligadas à área de Segurança.

Muitas são as mudanças que advém com o rompimento do ciclo da violência, muitas delas, influenciam a organização da vida familiar da mulher que decide denunciar seu agressor. A entrevistada revelou que dentre as principais mudanças vivenciadas estão, a sua saída do lar, abrigando-se em uma instituição pública destinada ao acolhimento de mulheres vítimas de violência em um município mais próximo, o abandono do trabalho e os agravamentos na saúde mental, como estresse, irritação, tendência ao isolamento social:

[...]Olha, pra mim mudou muita coisa, porque eu fiquei sem nada, eu tô dependendo de uma casa que não é minha, é um período de três meses, eu tô sem serviço, eu tô sem meus documentos pra procurar um serviço(...) Pra mim mudou muita coisa, eu tô com meus filhos, sozinha. Também mudou pro lado bom, porque eu sei que eu não vou ter aquele homem ali me aporrinhando todo o tempo, batendo boca, xingando, mandando, porque ele não pedia, mandava. Só que, eu ando muito irritada, eu não sei se é por causa das crianças, não sei se é por tudo isso, não sei se é por ter que tá encerrada, não poder sair e tal. Então pra mim mudou. Eu ando mais irritada, ando estressada (mulher rural, residente em um abrigo na área urbana).

O relato evidencia que o rompimento da violência requer da mulher uma atitude de coragem e principalmente a estruturação de uma rede de atendimento eficaz para assegurar a proteção e garantia dos direitos das mulheres. No que tange ao atendimento 
às mulheres previsto na Lei Maria da Penha, uma das questões fundamentais para garantir a integridade física e moral da mulher compreende o abrigamento nas situações envolvendo grave ameaça (situação em que se encontrava a mulher entrevistada). Diante desse cenário, uma das ações do Estado diz respeito à criação de Casas-Abrigo, que tem por atribuição prover, de forma provisória "medidas emergenciais de proteção em locais seguros para acolher mulheres em situação de violência doméstica e familiar sob risco de morte, acompanhadas ou não de seus filhos(as)" (SPM, 2011, p.11). Porém, uma casaabrigo foi fechada no RS durante o período da realização da pesquisa por falta de recursos e as casas estão, em geral, lotadas, não conseguindo atender à demanda. No interior e zona rural, a situação se agrava devido à inexistência de abrigos, o que implica mudança de endereço de residência. No Rio Grande do Sul existem 497 municípios e apenas 12 casasabrigos.

No entanto, quando não há suporte do Estado, a violência adquire formas complexas e de caráter multifacetado na vida cotidiana. Esse fenômeno naturalizado estende-se às questões complexas que envolvem não somente à falta de uma rede especializada, mas a cultura em todos os seus segmentos, seja em questões religiosas, no Estado e nas formas como agem suas instituições, nas interações sociais e econômicas e de classe. Estas, no entanto, evidenciam à discriminação em todos os aspectos seja quanto à posse da terra e sobrecarga feminina no trabalho, as quais são justificadas pelas relações assimétricas de gênero. Dessa forma, perpetuam-se ás desigualdades entre homens e mulheres, corroborando para a legitimação masculina no que tange à divisão sexual do trabalho no âmbito da agricultura e no trabalho doméstico.

[...] Eu levanto às 6h30min e vou pras vacas, nem tomo café, vou direto nas vacas. 9 h30min vou lavar as roupas, e faço todo meu serviço dentro de casa, faço a comida, preparo o chimarrão pra meio dia, isso em 5 minutos. Eu e meu marido, pela uma e pouco, saímos para a lavoura, lidamos na lavoura, $5 \mathrm{~h} 30 \mathrm{~min}$ estamos nas vacas de novo. E no outro dia, tudo de novo, é de 12 em 12 horas, sempre trabalhando (M- G, 26.05.2013).

[...] Geralmente trabalho de 12 a 14 horas por dia, começa antes do café, e termina depois de lavar a louça da janta. Depende da atividade de cada uma. Depende do que cultiva, depende se da uma dormida depois do almoço ( $M-G, 26.05 .2013$ ).

[...] aposentadoria rural das mulheres, agora quem tem 55 anos aposenta, ainda tem mulher que o marido quer pegar o salário dela e mandar no salário dela (M-LR) 04.08.2015.

As narrativas expressam claramente à assimetria entre a divisão do trabalho e às 
relações de subordinação e dominação masculina nesse contexto. Essa assimetria de poder 'tem sua origem na divisão de papéis sociais entre homens e mulheres, ou seja, uma norma social que admite uma distribuição desigual de privilégios, direitos e deveres dentro do ambiente doméstico como no ambiente público. A influência da cultura patriarcal, nas sociedades ocidentais, permeia o cotidiano privado. Dessa forma, as relações sociais de gênero constituem-se sob o prisma da reprodução e da socialização das desigualdades existentes entre homens e mulheres.

Segundo Minayo (2005), a naturalização da violência de gênero é característica fundamental da cultura ocidental, o tipo de machismo que orienta a cultura ocidental exerce grande influência nas relações sociais entre homens e mulheres, culminando em grande parte na violência devido à naturalização do fenômeno:

\begin{abstract}
A concepção do masculino como sujeito da sexualidade e o feminino como seu objeto é um valor de longa duração da cultura ocidental. Na visão arraigada no patriarcalismo, o masculino é ritualizado como o lugar da ação, da decisão, da chefia da rede de relações familiares e da paternidade como sinônimo de provimento material: o "impensado" e o "naturalizado" dos valores tradicionais de gênero. Da mesma forma e em consequência, o masculino é investido significativamente com a posição social (naturalizada) de agente do poder da violência, havendo, historicamente, uma relação direta entre as concepções vigentes de masculinidade e o exercício do domínio de pessoas, das guerras e das conquistas. (MINAYO, 2005. p. 23-24).
\end{abstract}

O panorama histórico do fenômeno em questão, diz respeito à naturalização dessa condição. Segundo Lobo (2011, p. 55), "convém pensar que a divisão sexual do trabalho como uma forma de construção social está diretamente ligada à esfera da reprodução e produção". Dessa forma, as mulheres estariam mais aptas à realização de trabalhos "secundários", próprios do universo feminino. Assim, na contemporaneidade ainda se reproduz o ideal de mulher submissa, logo, a divisão de tarefas domésticas e o trabalho fora de casa tornam-se um grande desafio às mulheres, no que se refere às conquistas de direitos. Muitas das tarefas realizadas pelas mulheres rurais ainda são vistas como ajuda, principalmente aquelas ligadas ao trabalho na roça, como o cuidado com os animais e colheita e cultivo de alimentos, já as atividades exercidas no âmbito doméstico, são vistas como tarefas quase que exclusivamente femininas.

Dessa forma, a opressão vivenciada pelas mulheres tomam variadas formas, ou seja, a sobrecarga de trabalho que se insere em seu cotidiano, definida pelo modo social, isto é, a sociedade dita o que é trabalho feminino e o distingue do trabalho masculino. 
Devido a essa estrutura social, muitas mulheres deixam de viver sua vida em prol do "cuidar" algo já imposto às mulheres e tido como natural. A ideologia patriarcal dita as regras para a conduta familiar, assim, o patriarcado, como organização social de poder, "baseia-se no controle e no medo, atitude/sentimento que forma um ciclo vicioso" (SAFFIOTI, 2004, 121). O que caracteriza a violência de gênero é justamente essa assimetria entre homens e mulheres, ela é considerada como qualquer ato que resulta ou possa resultar em dano ou sofrimento físico, sexual ou psicológico à mulher. Conforme Meneghel e Kronbauer (2005) a violência de gênero assume outras formas, quais sejam: ameaças, coerção, privação de liberdade, ainda que conforme os autores, as privações de liberdade podem ser dirigidas tanto na esfera doméstica, como na esfera pública. A privação de liberdade foi alvo de muitas queixas evidenciado pelas lideranças rurais ao narrarem o cotidiano de muitas mulheres das quais fazem parte da comunidade:

[...] casos assim que o homem tem um ciúme da mulher, e ai não deixa ela sair nem com as irmãs... chega em casa e ele está com um bicão todo entornado... "ainda vou me incomodar depois, então fico em casa(M-LR 04.08.2015).

[...] outros dizem "Ah, tá sempre saindo, tá sempre saindo sozinha..." (M-LR 04.08.2015)".

[...] Olha que tem muita mulher, e nova, de 40 e poucos anos, que para sair tem que pedir para o marido e ainda muitas vezes desiste de ir aos lugares, de participar, porque diz que eles se emburram, ficam brabos, eles não fazem essa coisa de violência de bater e xingar, mas ficam emburrados com elas tudo(M-LR 04.08.2015).

Evidencia-se nas narrativas que o sentimento de posse, em detrimento do feminino, permeia o cotidiano das mulheres que vivem no campo. As relações conjugais mostram que o exercício do poder ocorre de forma assimétrica, delegando o poder de decisão ao homem. Assim, muitas mulheres que residem nas zonas rurais, segundo a nossa pesquisa, costumam submeter-se às vontades do marido para evitar, do que contrariar sua vontade. $\mathrm{O}$ isolamento social e a própria subalternidade da mulher perante essa forma de violência pode atingir a capacidade das mulheres na tomada de consciência e até mesmo na busca de apoio, pois, além, desses fatores, a submissão é tida como algo natural, aceitável socialmente, o quê consequentemente as tornam mais vulneráveis a outras formas de violência.

São considerados como violência de gênero: os castigos, maus tratos, violência sexual, violência verbal, patrimonial, e também a psicológica. Assim, até o início dos anos 
1990, a violência de gênero foi reconhecida como um problema de saúde pública pela Organização Mundial de Saúde, que a considera um dos tipos mais generalizados de abuso de direitos humanos. Quanto à violência de gênero, esta abrange várias modalidades, doméstica, familiar e contra a mulher; ela advém de um modo de organização social, que privilegia o masculino em detrimento do feminino (SAFFIOTI, 2004).

Muitas das violências praticadas contra as mulheres são aceitas socialmente como algo naturalizado, assim as violências de caráter físico, como maus tratos e outras formas de abusos, fazem parte da história de cada mulher onde narram de forma natural e normal terem assistido a episódios de violência, ou justificam a própria violência do companheiro.

[...] é muito naturalizado, porque elas vêm... a grande maioria apanhava do pai, o pai batia na mãe, então é uma coisa muito natural... Só quando isso se torna um risco de vida de ameaça de morte, de ir para as vias de fato, tipo tentativa de homicídio... aí que elas se dão conta de toda a situação.(M-P)04.08.2015

[...] É como se fosse um papel estabelecido. "Ele é o provedor, eu não preciso fazer nada, eu sou"... mas também não é nada não é. Não faço nada e eu também não sou nada (M-P)04.08.2015

[...]tudo tão naturalizado que gera casos crônicos... chegam aqui num nível de falta de dignidade... mulheres que viveram 20 anos com o companheiro agressor, dez anos, muitos anos. E se não é com aquele companheiro, vem de famílias onde o pai, a referência masculina é um agressor né. Então, assim, com isso eu te digo que é naturalizado né, o conceito de... o que que é violência[...](M-P 04.08.2015).

As falas deixam claramente explícitas as relações hierárquicas próprias do regime patriarcal, ou seja, o modo como a sociedade capitalista se organiza, delegando o poder ao masculino em detrimento do feminino. Toda essa forma de sociabilidade incide de forma direta e indiretamente nas atitudes e decisões das mulheres, quando essas passam a conviver com as mais variadas formas de violência, por exemplo, o medo e a vergonha, são alguns dos fatores obstaculizadores à renúncia de um relacionamento violento.

Dessa forma, o patriarcalismo contribui para a sujeição das mulheres em vários aspectos, ou seja, algumas mulheres que se encontram em situação de violência, costumam estrategicamente permanecer em suas relações assimétricas por vários fatores que não devem ser ignorados; em muitos dos casos, possuir filhos pequenos torna-se um fator importante para que a mulher permaneça em situação de violência, a dependência econômica, e o próprio não reconhecimento das situações de opressão vivenciadas como violência, contribuem para o processo de naturalização das relações violentas. As narrativas dos profissionais que lidam diretamente com as mulheres evidenciam essas situações: 
[...]são mulheres submissas aquele agressor, com pouquíssima formação, sem profissão efetiva, no caso, donas de casa, cuidadoras do lar, dos filhos[...](M-P 04.08.2015).

[...] na maioria dos casos são mulheres que não tem um trabalho, não tem uma autonomia (M-P 04.08.2015).

[...] Deu para pagar as contas do banco e sobrou isso, é assim que funciona, e geralmente é para o fumo. Então é assim, mais na mão do homem. O talão de cheque, o cartão tá só na mão do homem (M-G 07.07.2015).

As narrativas acima expressam que as relações de gênero na contemporaneidade, adquirem caráter multidimensional em relação à disparidade de direitos entre homens e mulheres. O enfrentamento à violência contra as mulheres requer o olhar atento a esse caráter multidimensional, que assume o fenômeno. A superação da violência de gênero necessita de políticas públicas transversais, ou seja, politicas de habitação, trabalho, educação, isto é, políticas que dêem conta de reduzir as desigualdades entre homens e mulheres. Segundo Melo (2005, p.14), “existe um maior grau de pobreza entre as mulheres em relação aos homens, provocado pelos novos arranjos familiares", aumento do número de famílias chefiadas por mulheres nas últimas décadas. No entanto, o grau de pobreza entre as mulheres é um fator preocupante, as mulheres negras e pardas são as mais prejudicadas nesse sistema. No entanto, esses fatores não garantem a autonomia feminina, ainda há uma forte cultura que prega que o homem é o principal provedor da família. Nessa perspectiva, sinaliza Melo:

Para as mulheres, esta realidade de carências é mais aguda, uma vez que elas realizam uma gama enorme de atividades não remuneradas, seja no âmbito mercantil, seja no seio da família, pela dedicação às atividades do lar que as fazem ser majoritariamente dependentes da provisão masculina para o sustento de suas famílias. (MELO, 2005, p.14).

Quanto às atividades exercidas no campo, Mesquita e Mendes (2012), definem a agricultura como "um conceito utilizado para caracterizar as unidades de produção rural, estruturadas no trabalho familiar, que se identificam pela relação entre terra, trabalho e família". Ainda sustentam as autoras que a origem de sua história está relacionada com as transformações sociais e econômicas evidenciadas no campo a partir da modernização agrária ocorridas no Brasil e no mundo no Pós- Guerra. Com a chegada de novas tecnologias, a migração do campo para a cidades provocou, de certa forma, mudanças no meio rural, principalmente para o pequeno produtor(a), invisibilizado(a) pelas políticas 
públicas. Desse modo, evidencia-se um atraso econômico no meio rural, o que provoca uma disparidade social em relação aos sujeitos que vivem na cidade.

Sob esse aspecto, a questão da desigualdade de gênero no meio rural, é sentida no trabalho, como já explicitado na jornada cotidiana da mulher no meio rural, e muitas vezes invisibilizada, pois muitas mulheres chegam a ter a tripla jornada de trabalho, porém, o trabalho exercido fora do ambiente doméstico, ou seja, no plantio e até mesmo na colheita, são atividades vistas como "ajuda". Tal descrição, segundo Herrera (2013), tem sua justificação, no que se enquadra como trabalho pesado e trabalho leve e não raro, as mulheres rurais executam também trabalhos considerados pesados.

No entanto, o trato dessas diferenças sentidas nas atividades cotidianas, tem sua origem nas relações sociais baseadas nas diferenças de gênero, a sociedade patriarcal, que impôs regras de sociabilidade definindo comportamentos e traços culturais baseados nessas diferenças, uma delas é o papel que a mulher ocupa na sociedade, assim a essa forma de sociabilidade "se sustenta em uma economia domesticamente organizada, sendo uma maneira de assegurar aos homens os meios necessários à produção diária e à reprodução da vida" (CUNHA, 2014, p.154).

Para Pateman (2013, p. 62),

[...] o patriarcalismo se baseia no apelo à natureza e no argumento de que a função natural da mulher de procriar prescreve seu lugar doméstico e subordinado na ordem das coisas". Dessa forma, a história traduz a realidade desigual vivenciada pelas mulheres em relação ao homem. Constata-se que o cotidiano das mulheres sempre esteve atrelado à sujeição, à submissão e à dominação masculina.

A emancipação e autonomia das mulheres vão além da inserção da mulher no mercado de trabalho, pois implica uma transformação na organização social e nos valores que a sustentam. Os processos emancipatórios que possibilitam à autonomia da mulher estão determinados por fatores estruturais e conjunturais de uma sociedade. A sociedade capitalista, em sua forma mais arcaica, busca a expansão da força de trabalho para a acumulação de capital e, consequentemente atravessa barreiras geográficas e culturais, corrobando para a desigualdade de gênero em todas as esferas.

Desse modo, as políticas sociais constituem um campo contraditório, pois ao mesmo tempo em que buscam atender às necessidades da população, configuram-se como 
instrumento que assegura a reprodução do capital através da exploração da força de trabalho.

\section{Considerações finais}

As relações de gênero no contexto rural, ainda são pouco exploradas, porém, os poucos estudos sobre o tema revelam as diversas situações que as mulheres do campo enfrentam no seu cotidiano, que vão desde as especificidades no modo de vida, tanto no contexto familiar, como no social e as próprias questões que envolvem o trabalho, seja ele: o doméstico ou no campo.

Dessa forma, o entendimento do fenômeno da violência contra a mulher, mais especificamente da mulher que vive e trabalha no contexto rural, requer entender essas relações, em seus aspectos culturais, sociais e econômicos, mas principalmente compreender o lugar social que cada mulher ocupa, seus modos e condições de vida e as dificuldades de rompimento que são agravadas pela falta de acesso às informações e às políticas públicas de prevenção à violência contra a mulher. Além disso, as especificidades encontradas na cultura do meio rural nos municípios estudados denota uma maior visibilidade de traços fortemente marcados pelo poder heteronormativo nas relações de gênero, fator esse que corrobora para a perpetuação de uma sociedade machista e patriarcal e se estende às instituições que deveriam protegê-las.

As narrativas sinalizaram que o acesso às políticas públicas na zona rural, possui uma considerável diferença em relação à zona urbana, uma vez que a maior participação da sociedade civil organizada na elaboração e a formulação de políticas concentra-se nos grandes centros urbanos. Outro fator demonstrado foi a dificuldade de acesso às políticas públicas pelas mulheres rurais. O distanciamento das residências até a rede de proteção, que geralmente localiza-se no centro da cidade, significa muitas vezes que as mulheres percorrem quilômetros em busca de apoio. Esses fatores, associados às dificuldades que as mulheres rurais encontram como a falta de informação e dificuldade de acesso ao transporte constituem-se em obstaculizadores na busca da rede e na tomada de decisão para ruptura da violência. A invisibilidade do trabalho da mulher no campo, configurandose como "ajuda" também constitui-se em uma violência invisibilizada. 
Urge a necessidade de fortalecer coletivos de mulheres no campo como o movimento das mulheres campesinas, potencializar a busca ativa através de unidades móveis itinerantes de atendimento como já existem em alguns CRAS nas zonas rurais e romper com o silêncio em torno do fenômeno da violência no campo, em suas múltiplas expressões.

\section{REFERÊNCIAS}

ALMEIDA, S. S. Essa violência mal-dita. In: ALMEIDA, Suely Souza de. (Org.). Violência de gênero e políticas públicas. Rio de Janeiro: UFRJ, 2007.

BARBOSA, E.F. A técnica de grupos focais para obtenção de dados qualitativos. [S.I.]: Instituto de Pesquisa e Inovações Educacionais, 1999. Disponível em: <http://www.educativa.org.br> Acesso em: 30 ago. 2016.

BARDIN, L. Análise de Conteúdo. Lisboa: Edições Lisboa, 1977.

BRASIL. Secretaria de Políticas para Mulheres. Secretaria Nacional de Enfrentamento à Violência contra as Mulheres. Diretrizes Nacionais para o Abrigamento de Mulheres em Situação de Risco e Violência. Brasília, 2011. Disponível em: <https://www12.senado.leg.br/institucional/omv/entenda-a-violencia/pdfs/diretrizesnacionais-para-o-abrigamento-de-mulheres-em-situacao-de-risco-e-de-violencia>. Acesso em: 1 abr. 2017.

CASTILLO, J. J. Snowball Sampling. Retrieved [Date of Retrieval] from Experiment Resources on March 27, 2017. Disponível em: <http://www.experimentresources.com/snowball-sampling.html>. Acesso em: 12 maio 2017.

CLADEM - COMITÊ LATINO-AMERICANO E DO CARIBE PARA A DEFESA DOS DIREITOS DA MULHER. Relatório Nacional Brasileiro sobre a Situação da Mulher. In: XXXI ASSEMBLÉlA DE DELEGADAS DA COMISSÃO INTERAMERICANA DE MULHERES, 31., Punta Cana. Out. 2002. Disponível em: <http:// www.cladem.org>. Acesso em: 20 mar. 2017.

CUNHA, B. M. Violência contra a mulher, direito e patriarcado: perspectivas de combate à violência de gênero. Disponível em: <http://www.direito.ufpr.br/portal/wpcontent/uploads/2014/12/Artigo-B\%C3\%A1rbara-Cunha-classificado-em-7\%C2\%BAlugar.pdf>. Acesso em 14 de março de17.

GROSSI, P. K. et al. O enfrentamento da violência contra a mulher rural: desafios para as políticas públicas. In: JORNADA INTERNACIONAL DE POLÍTICAS PÚBLICAS, 7., 2015, São Luís, Maranhão. Anais... São Luís, ago. 2015. Disponível em: http://www.joinpp.ufma.br/jornadas/joinpp2015/pdfs/eixo7/o-enfrentamento-da-violenciacontra-a-mulher-rural-desafios-para-as-politicas-publicas.pdf. Acesso em: 10 dez. 2017. 
HERRERA, K. M. Uma análise do trabalho da mulher rural através da perspectiva da multifuncionalidade agrícola. 2013.2 Disponível <http://www.fg2013.wwc2017.eventos.dype.com.br/resources/anais/20/1373328660_AR QUIVO_ArtigoFazendogenerofinal.pdf>. Acesso em: 15 mar. 2017.

LOBO, E. S. A classe operária tem dois sexos: trabalho, dominação e resistência. 2. ed. São Paulo: Fundação Perseu Abramo, 2011.

MARCONI. M. A.; LAKATOS, E. M. Técnicas de pesquisa. São Paulo: Atlas, 1999.

MELO, H. P. A invisibilidade do trabalho feminino nas estatísticas, 2005. Disponível em: <www.ibge.gov.br/confest_e_confege/...trabalhos/.../232-1.doc>. Acesso em: 4 mar. 2017.

MESQUITA, L. A. P.; MENDES, E. P. P. Mulheres na Agricultura Familiar: a comunidade Rancharia, Campo Alegre de Goiás(GO), 2012. Disponível em: <http://www.lagea.ig.ufu.br/xx1enga/anais_enga_2012/eixos/1104_1.pdf>. Acesso em Julho de 2016.

MINAYO, M. C. S. O desafio do conhecimento: pesquisa qualitativa em saúde. 5. ed. São Paulo: Hucitec-Abrasco, 1998.

. Laços perigosos entre machismo e violência. Ciência \& Saúde Coletiva, v. 10, n. 1, p. 18-34, 2005. Disponível em: <www.scielosp.org/pdf/csc/v10n1/a03cv10n1> Acesso em: 10 jan. 2016.

PATEMAN, C. Críticas feministas à dicotomia público/privado. In: MIGUEL, F. L.; BIROLI, F. (Org.). Teoria política feminista: textos centrais. Vinhedo: Horizonte, 2013.

PERES, M. F. T. Prevenção e controle: oposição ou complementaridade para a redução da violência? Revista Ciência e Cultura, v. 54, n. 1, p. 54-55, jul./set. 2002. Disponível em: <http://intertemas.unitoledo.br/revista/index.php/ETIC/article/viewFile/2596/2302>. Acesso em: 30 maio 2015.

SAFFIOTI, H. I. B. Gênero, patriarcado, violência. São Paulo: Fundação Perseu Abramo, 2004. (Coleção Brasil Urgente).

. A síndrome do pequeno poder. In: AZEVEDO, M. A.; GUERRA, V. N. (Org). Crianças Vitimizadas: a síndrome do pequeno poder. São Paulo: Iglu, 2007. 